

University of Central Florida

STARS

Faculty Bibliography 2010s

Faculty Bibliography

$1-1-2010$

\title{
Double-stage glass transition in a metallic glass
}

Dmitri V. Louzguine-Luzgin

Ichiro Seki

Tokujiro Yamamoto

Hitoshi Kawaji

C. Suryanarayana

University of Central Florida

See next page for additional authors

Find similar works at: https://stars.library.ucf.edu/facultybib2010

University of Central Florida Libraries http://library.ucf.edu

This Article is brought to you for free and open access by the Faculty Bibliography at STARS. It has been accepted for inclusion in Faculty Bibliography 2010 s by an authorized administrator of STARS. For more information, please contactSTARS@ucf.edu.

\section{Recommended Citation}

Louzguine-Luzgin, Dmitri V.; Seki, Ichiro; Yamamoto, Tokujiro; Kawaji, Hitoshi; Suryanarayana, C.; and Inoue, Akihisa, "Double-stage glass transition in a metallic glass" (2010). Faculty Bibliography 2010 s. 462. https://stars.library.ucf.edu/facultybib2010/462

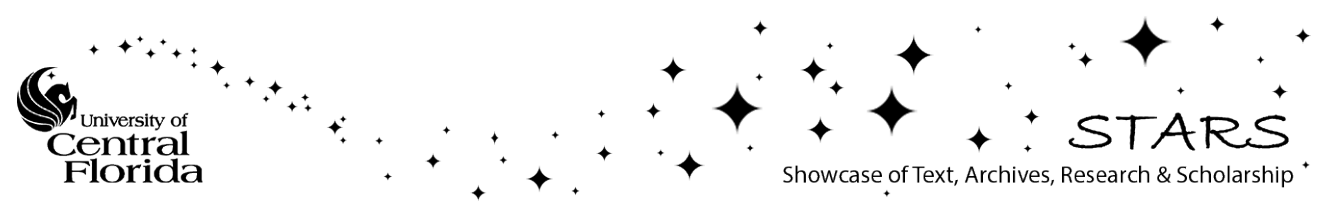




\section{Authors}

Dmitri V. Louzguine-Luzgin, Ichiro Seki, Tokujiro Yamamoto, Hitoshi Kawaji, C. Suryanarayana, and Akihisa Inoue 


\title{
Double-stage glass transition in a metallic glass
}

\author{
Dmitri V. Louzguine-Luzgin,,${ }^{1,2, *}$ Ichiro Seki, ${ }^{2}$ Tokujiro Yamamoto ${ }^{2}$ Hitoshi Kawaji, ${ }^{3}$ C. Suryanarayana, $, 2,4$ and \\ Akihisa Inoue ${ }^{1,2}$ \\ ${ }^{1}$ WPI Advanced Institute for Materials Research, Tohoku University, Katahira 2-1-1, Aoba-Ku, Sendai 980-8577, Japan \\ ${ }^{2}$ Institute for Materials Research, Tohoku University, Katahira 2-1-1, Aoba-Ku, Sendai 980-8577, Japan \\ ${ }^{3}$ Materials and Structures Laboratory, Tokyo Institute of Technology, 4259 Nagatsuta-cho, Midori-ku, Yokohama 226-8503, Japan \\ ${ }^{4}$ Department of Mechanical, Materials and Aerospace Engineering, University of Central Florida, Orlando, Florida 32816-2450, USA
}

(Received 12 February 2010; published 23 April 2010)

\begin{abstract}
Glass-transition region is still a somewhat "dark area" in the field of materials science. In order to shed more light on this phenomenon, the glass-transition behavior was studied in a $\mathrm{Zr}_{55} \mathrm{Cu}_{30} \mathrm{Al}_{10} \mathrm{Ni}_{5}$ glassy alloy by monitoring its specific-heat capacity measured using a differential scanning calorimeter during heating in a step-scan mode. This reduces the influence of kinetic effects which shield the transition. It is suggested that two types of relaxation (likely related to the diffusivities of different alloying elements $\mathrm{Cu}$ and $\mathrm{Ni}$ on the one hand as well as $\mathrm{Zr}$ and $\mathrm{Al}$ on the other hand) take place and compete in the glass-transition region.
\end{abstract}

DOI: $10.1103 /$ PhysRevB.81.144202

PACS number(s): 64.70.pe, 64.70.kj

\section{INTRODUCTION}

Active research on metallic glassy alloys (or metallic glasses) started since the first synthesis of an amorphous phase by rapid solidification of an Au-Si alloy in $1960 .{ }^{1}$ Depending on the glass-forming ability (GFA) of the system, glassy/amorphous alloys can be produced using different methods. Materials having a very low GFA, e.g., pure metals, can be prepared in the amorphous state by condensation from the vapor phase ${ }^{2}$ which is highly power intensive and not efficient. Much more effective is rapid (compared to conventional metallurgical methods) solidification from a liquid phase $^{3}$ by techniques such as melt spinning, $\mathrm{Cu}$-mold casting, liquid forging, and so on. A large number of bulk glassy alloys (also called bulk metallic glasses) defined as threedimensional massive glassy (amorphous) articles with a size of not less than $1 \mathrm{~mm}$ in any dimension $(10 \mathrm{~mm}$ by another definition) have also been produced during the last 20 years in the thickness range of up to $72 \mathrm{~mm}$ by using various casting processes. ${ }^{4-7}$

Even though metallic glasses have a liquidlike structure, they behave as solids in general but also have similarities with solids and with liquids. The packing density of noncrystalline structures is an important geometrical factor influencing GFA. The importance of efficient atomic packing for the formation of metallic glasses was shown recently. ${ }^{8,9}$ It has been emphasized that specific radius ratios of the constituent elements are preferred for the formation of metallic glasses at certain composition ranges.

Glass formation is a complex phenomenon. Upon fast enough cooling of a liquid alloy, crystallization is suppressed and it solidifies producing a glass. ${ }^{10}$ The properties of the liquid and glass vary continuously and the specific volume of a crystal at a given temperature is lower than that of the glassy phase.

The glass-transition phenomenon in metallic glasses has been studied extensively for many years. ${ }^{11-14}$ Nevertheless, the glass-transition process is still somewhat a "dark area" in the field of materials science. The nature of the glassy state and of the glass transition is not clear and is still being in- vestigated. An important question which is still not fully answered is: do glassy and liquid phases belong to essentially the same phase, just observed at different temperatures, or are they two completely different phases? In other words, does the liquid $\rightarrow$ glass phase transformation (called glass transition) and the reverse (glass $\rightarrow$ liquid transformation) indeed take place or it is just the reaction of the machine on different relaxation times. ${ }^{15,16}$ A thermodynamic treatment of glass transition has been suggested by Kauzmann. ${ }^{17}$ Several theories are used to describe the glass transition, ${ }^{18,19}$ though none is so far comprehensive. It is known that the temperatures of the beginning/start and finish of the glass transition depend on the heating rate. At lower heating rates, $T_{\mathrm{g}}$ is lower and the width of the glass-transition region decreases.

In the present study, we have investigated the glasstransition phenomenon in a $\mathrm{Zr}_{55} \mathrm{Cu}_{30} \mathrm{Al}_{10} \mathrm{Ni}_{5}$ glassy alloy. In order to minimize the kinetic effects associated with structural relaxation upon continuous heating, we have measured the specific-heat capacity as a material property, on annealing the glassy alloy for different times in a step-scan mode. Step-scan measurements allow one to equilibrate the glassy phase before each measurement. ${ }^{20}$ The studied alloy has a high enough GFA and stability of the supercooled liquid for such an investigation.

Another target was to test the relaxation behavior of the glassy phase toward the liquid phase in the glass-transition region and infer whether the glass transition is just a reaction of the instrument (DSC) on the characteristic time scales or whether the glassy phase indeed transforms gradually to the liquid state above the glass-transition temperature. With this purpose in mind, measurements have been made for different time scales in a step-scan mode.

\section{EXPERIMENTAL PROCEDURE}

The ingot of a $\mathrm{Zr}_{55} \mathrm{Cu}_{30} \mathrm{Al}_{10} \mathrm{Ni}_{5}$ alloy (the composition is given in nominal at. \%) was prepared by arc-melting mixtures of high-purity elemental metals $>99.9$ wt $\%$ purity in an argon atmosphere. Since crystallization of this alloy was found to be quite sensitive to the presence of impurities, ${ }^{21}$ 
pure metals were used to synthesize the samples in the present investigation. From this ingot, glassy ribbon samples of about $20 \mu \mathrm{m}$ in thickness and $1 \mathrm{~mm}$ in width were prepared by rapid solidification of the melt on a single copper roller at a tangential wheel velocity of $40 \mathrm{~m} / \mathrm{s}$.

The glass-transition phenomenon was studied on heating in a Perkin-Elmer Diamond DSC in a step-scan mode. The ribbon samples of glassy $\mathrm{Zr}_{55} \mathrm{Cu}_{30} \mathrm{Al}_{10} \mathrm{Ni}_{5}$ alloys were heated at a heating rate of $0.083 \mathrm{~K} / \mathrm{s}(5 \mathrm{~K} / \mathrm{min})$ while the annealing (waiting) time between steps was maintained at 60,600, and $1200 \mathrm{~s}$ (1 min, $10 \mathrm{~min}$, and $20 \mathrm{~min}$, respectively). The specific-heat capacity at constant pressure $\left(C_{\mathrm{p}}\right)$ was measured by using heat release $(\Delta H)$ at each heating step. The specific-heat capacity near a certain temperature (696 K) within the glass-transition region was measured on heating and cooling by $5 \mathrm{~K}$ separated by isothermal keep time of 60 s. In a separate run of the experiments, different heating rates of 0.05 and $0.167 \mathrm{~K} / \mathrm{s}(3$ and $10 \mathrm{~K} / \mathrm{min})$ were also used.

\section{RESULTS}

Figure 1(a) shows the variation in specific-heat capacity $C_{\mathrm{p}}$ of the alloy as a function of temperature on continuous heating in the DSC at a heating rate of $0.67 \mathrm{~K} / \mathrm{s}(40 \mathrm{~K} / \mathrm{min})$. The plot obtained is typical showing that the specific heat increases with increasing temperature suggesting that relaxation occurs initially and then crystallization sets in above $760 \mathrm{~K}$. The specific heat is found to increase more abruptly in the glass-transition temperature range of $660-720 \mathrm{~K}$. The specific heat remains virtually constant in the (supercooled) liquid state, and decreases to a low value (similar to that of the glassy state) on crystallization. It is also interesting to note that one can see a clear overshoot in the continuous $C_{\mathrm{p}}$ curve.

Figure 1(a) also shows the variation in specific heat with increasing temperature and for an annealing time of $1 \mathrm{~min}$ (60 s) per step. It is shown that $C_{\mathrm{p}}$ has an initial value below $25 \mathrm{~J} / \mathrm{mol} * \mathrm{~K}$ in the as-quenched glassy state and starts to increase more-or-less monotonically with temperature. The slope changes drastically starting from about $670 \mathrm{~K}$ and $C_{\mathrm{p}}$ reaches a maximum of about $38 \mathrm{~J} / \mathrm{mol} * \mathrm{~K}$ at about $700 \mathrm{~K}$ in the liquid state $\left(C_{\mathrm{p}}^{\mathrm{L}}\right)$. Similar plots were obtained when the annealing (hold) time was maintained at $10 \mathrm{~min}(600 \mathrm{~s})$ and 20 min (1200 s) Fig. 1(b). The $C_{\mathrm{p}}$ values measured at the annealing times of $1 \mathrm{~min}(60 \mathrm{~s}), 10 \mathrm{~min}(600 \mathrm{~s})$, and $20 \mathrm{~min}$ (1200 s) are referred to as $C_{\mathrm{p}}^{1}, C_{\mathrm{p}}^{10}$, and $C_{\mathrm{p}}^{20}$, respectively. The most stable value of $C_{\mathrm{p}}=38.22 \pm 0.06 \mathrm{~J} / \mathrm{mol} * \mathrm{~K}$ was obtained at $1 \mathrm{~min}(60 \mathrm{~s})$ annealing time and is taken as a reference value.

Depending on the annealing time, the (supercooled) liquid crystallizes forming crystalline phases and the specific-heat capacity in this case decreases back close to that of the glassy phase. One may also point out that no prolonged exothermic peak is noted below the glass-transition region upon the step-scan measurement compared to continuous heating [Fig. 1(a)]. Thus one can assume that the sample mostly relaxes during the annealing time of the measurement. One can also see that compared to continuous heating curve [Fig. 1(a)], no clear overshoot is seen in $C_{\mathrm{p}}^{1}$ produced in a stepscan mode.
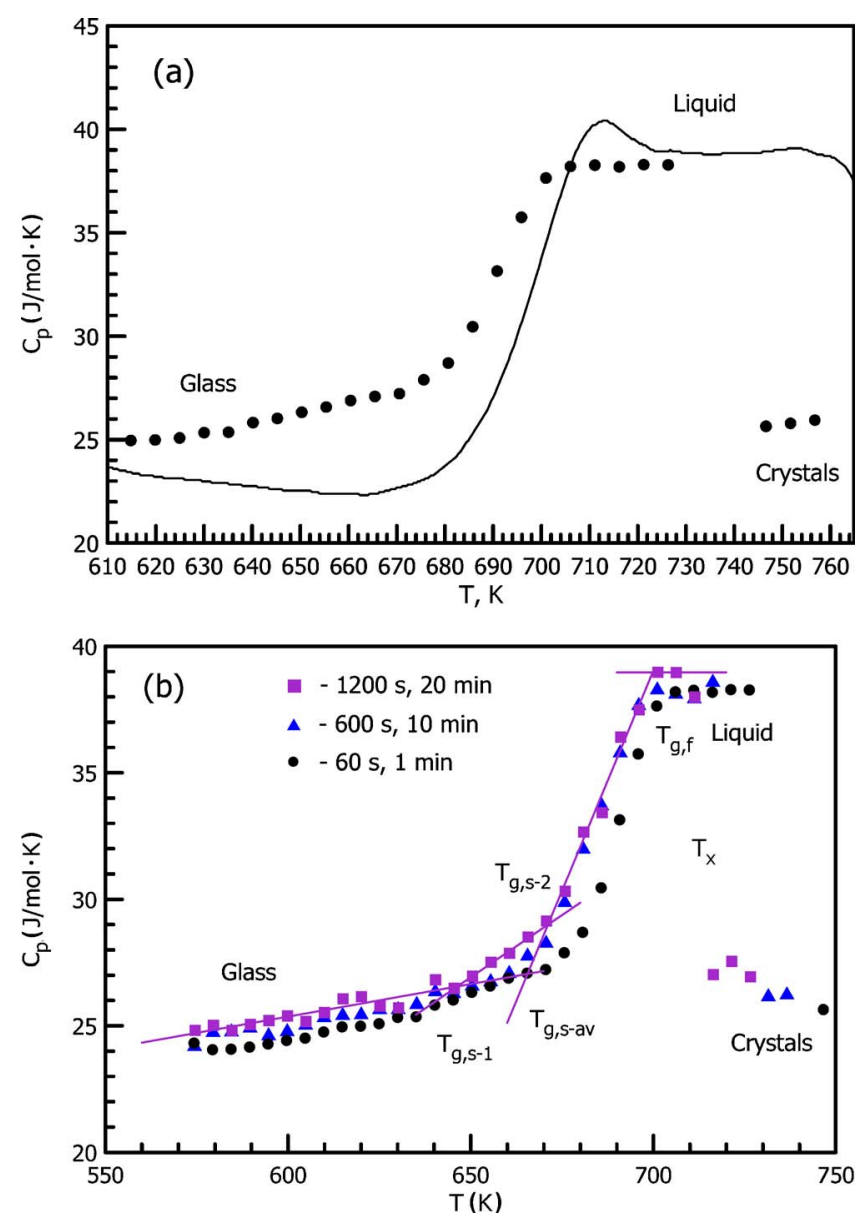

FIG. 1. (Color online) (a) Solid line $C_{\mathrm{p}}$ on continuous heating at $0.67 \mathrm{~K} / \mathrm{s}(40 \mathrm{~K} / \mathrm{min})$. Circles $-C_{\mathrm{p}}^{1}$ as a function of temperature measured in a step-scan way (heating rate $0.083 \mathrm{~K} / \mathrm{s}$ or $5 \mathrm{~K} / \mathrm{min}$ ). (b) $C_{\mathrm{p}}$ as a function of temperature and annealing time measured in a step-scan way (heating rate $0.083 \mathrm{~K} / \mathrm{s}$ or $5 \mathrm{~K} / \mathrm{min}$ ).

Unlike in the continuous mode of heating, the $C_{\mathrm{p}}$ curves in the step-scan mode change the slope several times and this is clearly illustrated for $C_{\mathrm{p}}^{20}$ in Fig. 1(b). One can distinguish several break points in the curves, which could be designated as the start of the glass-transition temperature (ergodicity making $\left.{ }^{22}\right)\left(T_{\mathrm{g}, \mathrm{s}}\right)$ consisting of $\left(T_{\mathrm{g}, \mathrm{s}-1}\right),\left(T_{\mathrm{g}, \mathrm{s}-\mathrm{av}}\right)$, and $\left(T_{\mathrm{g}, \mathrm{s}-2}\right)$ as well as finish $\left(T_{\mathrm{g}, \mathrm{f}}\right)$ glass-transition temperature. These temperatures could be obtained by drawing tangents to the plot below, inside and above the glass-transition region as shown by straight solid lines in case of $C_{\mathrm{p}}^{20}$ in Fig. 1(b). Clear existence of at least two slopes within the glass-transition region (especially at high enough annealing time of $20 \mathrm{~min}$ ) between $T_{\mathrm{g}, \mathrm{s}-1}$ and $T_{\mathrm{g}, \mathrm{f}}$ indicates two glass-transition processes: low- and high-temperature glass-transition processes which cannot be a result (or an artifact) of the machine used to determine the specific-heat values. The changes in slopes may actually indicate a competition between the $\alpha$ - and $\beta$-relaxation processes.

A very weak peak may also be noticed at about $615-620$ $\mathrm{K}$ in Fig. 1(b). This may indicate the beginning of the release of the excess volume upon structural relaxation leading to densification of the glass. According to the work of Yavari et 




FIG. 2. (Color online) The glass-transition and crystallization temperatures as well as the width of the glass-transition region $\left(\Delta T_{\mathrm{g}}\right)$ as a function of annealing time.

al., a significant decrease in volume of Zr-based alloys was noted in this temperature range. ${ }^{23}$

Figure 2 plots the variation in the different glass-transition temperatures $\left(T_{\mathrm{g}, \mathrm{s}-1}, T_{\mathrm{g}, \mathrm{s}-\mathrm{av}}, T_{\mathrm{g}, \mathrm{s} 2}, T_{\mathrm{g}, \mathrm{f}}, T_{x}\right)$, and $\Delta T_{\mathrm{g}}$ as a function of annealing (hold) time. It is interesting to note that while all the temperatures related to glass-transition decrease, the $\Delta T_{\mathrm{g}}$ values show a moderate increase with increasing annealing time. This is rather surprising since the temperature range is expected to be narrower at longer hold times. ${ }^{14}$ Further, from the trend of variation in crystallization temperature $\left(T_{x}\right)$ and $T_{\mathrm{g}, \mathrm{f}}$, it appears that, at annealing times longer than $20 \mathrm{~min}(1200 \mathrm{~s}), T_{x}$ will be lower than even $T_{\mathrm{g}, \mathrm{f}}$ and the sample will behave like an amorphous solid. This indicates the complex mechanism of glass transition in this alloy.

The relaxation velocity, $\Delta C_{\mathrm{p}} R$ related to the specific-heat capacity, of the liquid $C_{\mathrm{p}}^{\mathrm{L}}$ can be calculated using the relationship: $\Delta C_{\mathrm{p}} R=C_{\mathrm{p}}^{x}-C_{\mathrm{p}}^{1} / C_{\mathrm{p}}^{\mathrm{L}}-C_{\mathrm{p}}^{1}(x=10$ or 20$)$ and the values of $\Delta C_{\mathrm{p}} R$ for $C_{\mathrm{p}}^{20}$ and $C_{\mathrm{p}}^{10}$ are presented in Fig. 3, along with the absolute $\Delta C_{\mathrm{p}} A$ values. Absolute values of the relaxation velocity have a maximum close to $T_{\mathrm{g}, \mathrm{s}}$ while the values relative to $C_{\mathrm{p}}^{1}$ attain a maximum at close to $T_{\mathrm{g}, \mathrm{f}}$. As the ab-

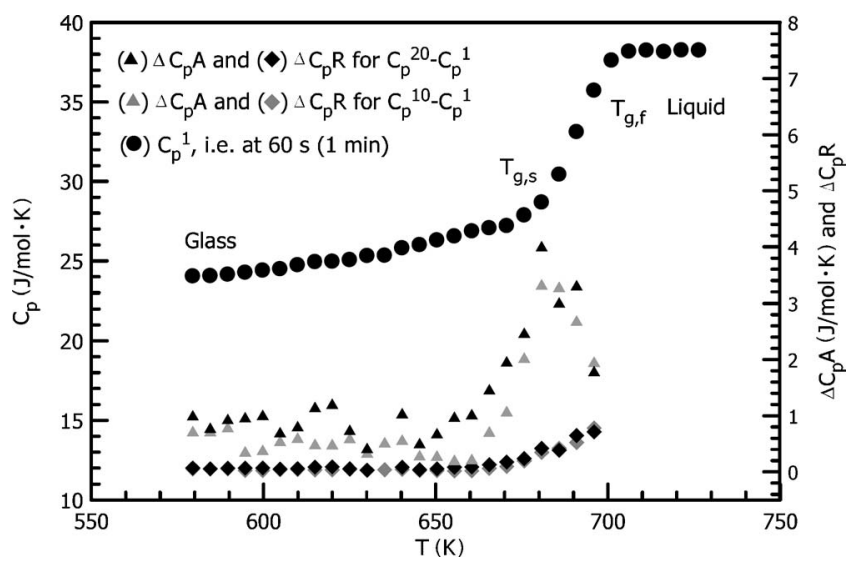

FIG. 3. Transition of glassy phase toward liquid phase as a function of annealing time. $\Delta C_{\mathrm{p}} A$ and $\Delta C_{\mathrm{p}} R$ are absolute and relative $C_{\mathrm{p}}$ difference values, respectively.
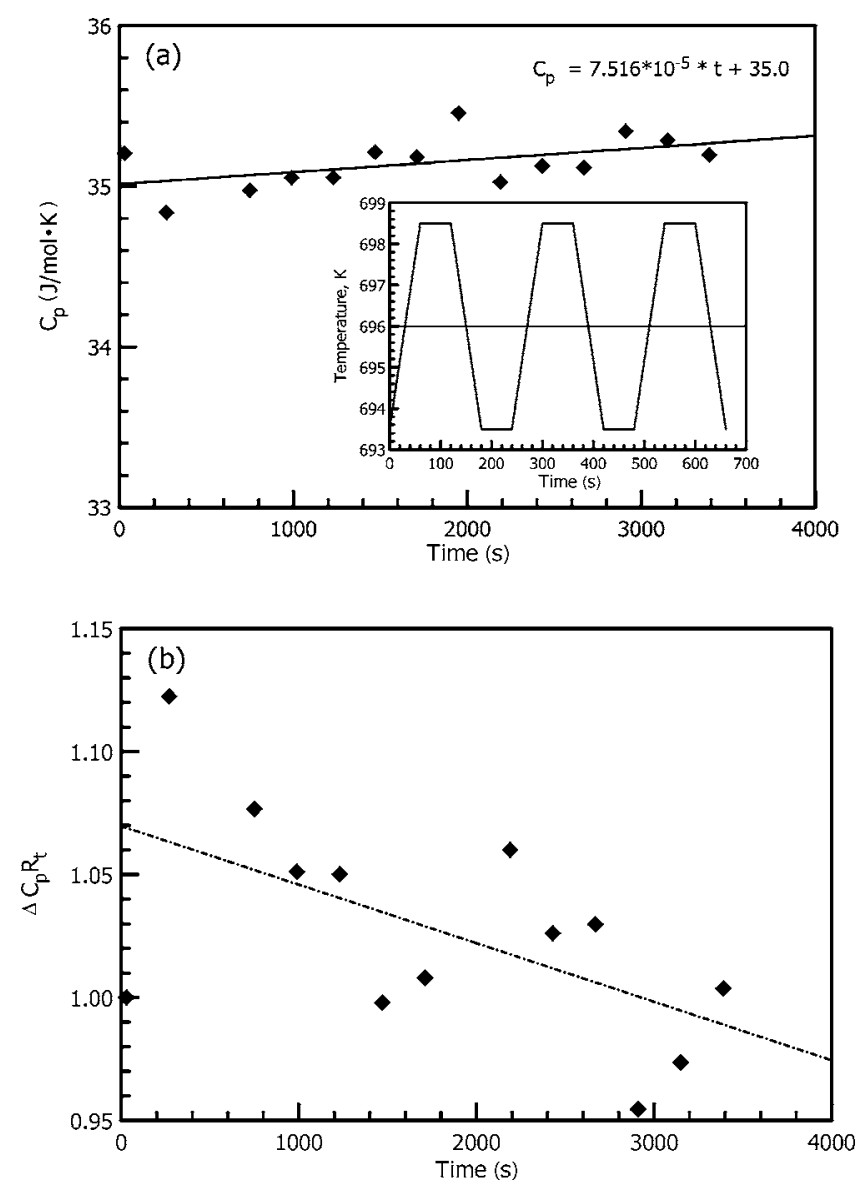

FIG. 4. (a) $C_{\mathrm{p}}^{1}$ at $696 \mathrm{~K}$ as a function of time measured on heating cycle. Heating scheme is illustrated in the inset and (b) the corresponding derived $\Delta C_{\mathrm{p}} R_{t}$ data.

solute difference between $C_{\mathrm{p}}^{20}$ and $C_{\mathrm{p}}^{10}$ is much smaller than the difference between $C_{\mathrm{p}}^{10}$ and $C_{\mathrm{p}}^{1}$, one can confirm that although transition of glassy phase toward liquid is a damped process it really takes place above $T_{\mathrm{g}, \mathrm{s}}$.

Figure 4 shows the relaxation behavior of the glassy alloy ribbon during a heating-cooling cycle around the temperature of $696 \mathrm{~K}$, which is in the glass-transition region. In this experiment, the sample was heated (or cooled) by $5 \mathrm{~K}$ in such a way that $696 \mathrm{~K}$ is an average value at a rate of 0.083 $\mathrm{K} / \mathrm{s}$, held there for $1 \mathrm{~min}(60 \mathrm{~s})$ of annealing time and then cooled (or heated). $C_{\mathrm{p}}^{1}$ was measured and the results are shown in Fig. 4. Both $C_{\mathrm{p}}$ and $\Delta C_{\mathrm{p}} R_{\mathrm{t}}$, calculated using the relationship $\Delta C_{\mathrm{p}} R_{t}=C_{\mathrm{p}(t)}^{1}-C_{\mathrm{p}}^{\mathrm{L}} / C_{\mathrm{p}(t=1)}^{1}-C_{\mathrm{p}}^{\mathrm{L}}$ are plotted as a function of time. In this relationship, $C_{\mathrm{p}(t)}^{1}$ is heat capacity at time $t, C_{\mathrm{p}}^{\mathrm{L}}$ is that of a liquid (taken $38.22 \mathrm{~J} / \mathrm{mol} * \mathrm{~K}$ ), and $C_{\mathrm{p}(t=1)}^{1}$ is heat capacity after $60 \mathrm{~s}$. Here the target was to examine the behavior of the glassy phase, when it is allowed to relax within the glass-transition region. With this repeated heating-cooling cycling, the $C_{\mathrm{p}}$ value of the glassy phase gradually increased toward the value of the liquid. In other words, glass tends to become a liquid with time.

Figure 5 shows $C_{\mathrm{p}}^{1}$ and relaxation time calculated using the viscosity data ${ }^{24}$ as a function of temperature obtained at a heating rate of $20 \mathrm{~K} / \mathrm{min}(0.33 \mathrm{~K} / \mathrm{s})$. It is generally expected that the glass transition takes place when the Maxwell relax- 


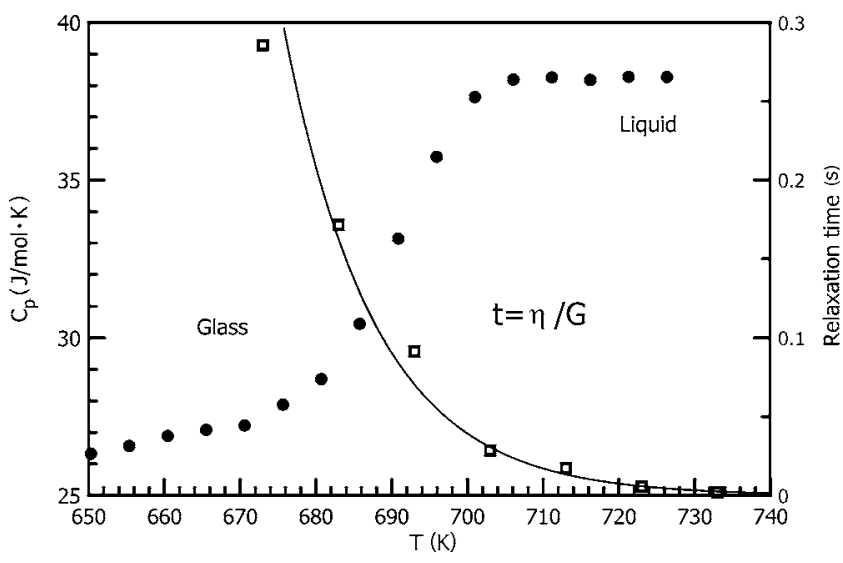

FIG. 5. $C_{\mathrm{p}}^{1}(\bullet)$ and relaxation time $(\square)$ calculated using viscosity data (Ref. 24) as a function of temperature.

ation time is on the order of $100 \mathrm{~s}$. Further, the viscosity value is expected to be about $10^{12} \mathrm{~Pa} * \mathrm{~s}$ at the start of glass transition on heating. However, in the present investigation, it is noted that the viscosity and calculated relaxation time at $T_{\mathrm{g}, \mathrm{s}}$ are rather low-about $10^{10} \mathrm{~Pa} * \mathrm{~s}$ and $0.3 \mathrm{~s}$, respectively, at $673 \mathrm{~K}$ (Ref. 24) and, these values change only about an order of magnitude within the glass-transition region. Of course, it is accepted that these values measured at $0.33 \mathrm{~K} / \mathrm{s}$ $(20 \mathrm{~K} / \mathrm{min})$ are far from equilibrium.

Figure 6 presents the variation in $C_{\mathrm{p}}$ and $\Delta C_{\mathrm{p}}$ as a function of temperature at different heating rates. Annealing time between the heating steps was $60 \mathrm{~s}$. Here, the values of $\Delta C_{\mathrm{p}}$ $\left(\Delta C_{\mathrm{p}}^{3-5}, \Delta C_{\mathrm{p}}^{5-10}, \Delta C_{\mathrm{p}}^{3-10}\right)$ are the absolute differences between the corresponding heat capacities $C_{\mathrm{p}}^{3}, C_{\mathrm{p}}^{5}$, and $C_{\mathrm{p}}^{10}$ measured at different heating rates of $3 \mathrm{~K} / \mathrm{min}, 5 \mathrm{~K} / \mathrm{min}$, and $10 \mathrm{~K} / \mathrm{min}$, respectively. These values are increasing slightly with the cooling rate.

Figure 7 shows the variation in $C_{\mathrm{p}}^{1}$ on heating and cooling as a function of temperature within the glass-transition range, at two different rates, viz., 5 and $10 \mathrm{~K} / \mathrm{min}$. There is only a very week, almost undetectable hysteresis in $C_{\mathrm{p}}$ on heating and cooling. A weak overshoot is also observed on heating at $5 \mathrm{~K} / \mathrm{min}$. The overshoot and the hysteresis relate the enthalpy relaxation in this glass.



FIG. 6. $C_{\mathrm{p}}^{3}, C_{\mathrm{p}}^{5}$, and $C_{\mathrm{p}}^{10}$ as a function of temperature. $\Delta C_{\mathrm{p}}^{3-5}$, $\Delta C_{\mathrm{p}}^{5-10}$, and $\Delta C_{\mathrm{p}}^{3-10}$ are the absolute differences between the corresponding heat capacities. Note that here the meaning of the superscript above $C_{\mathrm{p}}$ is slightly different than that in previous figures.


FIG. 7. (Color online) $C_{\mathrm{p}}^{1}$ on heating and cooling as a function of temperature at two different heating rates. (a) $5 \mathrm{~K} / \mathrm{min}$ and (b) 10 $\mathrm{K} / \mathrm{min}$.

\section{DISCUSSION}

The phenomenon of glass transition is very important in understanding the transformation behavior of a liquid into the glassy state. However, as mentioned earlier, there are several gaps in obtaining a clear picture of the glass transition, especially in metallic liquids. One may refer to Angell (Ref. 14), Ngai and Capaccioli, ${ }^{25}$ and Hodge ${ }^{26}$ for the issues that continue to puzzle the scientists. The present investigation has been undertaken to shed more light on this issue.

As shown in Fig. 1(b), two slopes were clearly observed within the glass-transition region between $T_{\mathrm{g}, \mathrm{s}-1}$ and $T_{\mathrm{g}, \mathrm{f}}$. These slopes indicate that two glass-transition processes are occurring one at a low temperature and the other at a high temperature. These changes in slopes representing the glasstransition processes are not the artifacts produced by the machine but they are genuine. The change in slopes may be explained on the basis of the different diffusivities of the constituent elements in the glass.

It is known that at low temperatures, diffusion of atoms by cooperative shearing is several orders of magnitude slower and therefore they move predominantly by atomic hopping. ${ }^{14,27}$ At higher temperatures, however, diffusion of $\mathrm{Ni}$ atoms becomes comparable to the hopping time. This is because Ni has a significantly higher diffusion coefficient 
$\left(D \sim 10^{-18} \mathrm{~m}^{2} / \mathrm{s}\right.$ at $\left.650 \mathrm{~K}\right)$ than $\mathrm{Al}\left(D \sim 5 \times 10^{-20} \mathrm{~m}^{2} / \mathrm{s}\right.$ at $650 \mathrm{~K})^{28}$ and therefore the time scale for shear of $\mathrm{Ni}$ atoms becomes comparable to the hopping time and the liquidlike motion is predominant for these atoms. According to the formula $(l=2 \sqrt{D t})$, where $l$ is the diffusion length, $D$ is the diffusion coefficient, and $t$ is the time, the diffusion length $(l)$ at $650 \mathrm{~K}$ is calculated to be $60 \mathrm{~nm}$ in $100 \mathrm{~s}$ for $\mathrm{Ni}$ which is about 200 interatomic distances while for $\mathrm{Al}$, the diffusion length corresponds to only $4 \mathrm{~nm}$ or nearly 10 interatomic distance. The behavior in Fig. 1 may illustrate that each alloying element undergoes a different transition range below which it moves in a solidlike manner. In fact, Egami ${ }^{29}$ suggests that glass transition in a multicomponent system does not occur uniformly but gradually over a range of temperature reflecting the inhomogeneity at the atomic level. Thus, based on the complexity of the alloy consisting of the different constituent elements which present in the glass, one may observe more than two slopes in the glass transition. If the number of steps is too large, due to the presence of small changes in the inhomogeneity in the entire glass, then a large number of changes in the slope will occur at very short intervals, and consequently the glass transition will appear relatively smooth. On the other hand, if the inhomogeneity level is relatively high, i.e., on a scale larger than the atomic level (but the glass is still "homogeneous" on a macroscopic level), then it is possible that clear changes in slope may be observed in the glass transition. It is very likely that is what is happening in the present alloy.

Based on the above calculations, $650 \mathrm{~K}$ may be considered as a freezing temperature for $\mathrm{Ni}$ atoms (and possibly for $\mathrm{Cu}$ also since both $\mathrm{Cu}$ and $\mathrm{Ni}$ are quite similar in many respects) whereas $\mathrm{Al}$ atoms become mobile only above about $670 \mathrm{~K}$ when its $D_{\mathrm{Al}}$ reaches about $10^{-18} \mathrm{~m}^{2} / \mathrm{s} .{ }^{28}$ This may explain the widening of the glass-transition range in Fig. 2 because $T_{\mathrm{g}, \mathrm{s}-1}$ decreases with increase in the annealing time while $T_{\mathrm{g}, \mathrm{f}}$ is related to an ergodic liquid and is less dependent on the annealing time.

Relaxation speed ${ }^{30}$ in isothermal conditions at $696 \mathrm{~K}$, which is about $0.3 \mathrm{~J} / \mathrm{mol} * \mathrm{~K}$ at about $3000 \mathrm{~s}$ (Fig. 4), roughly corresponds to the difference obtained upon stepscan heating.

Relaxation of the glassy phase toward liquidlike behavior takes place in the glass-transition region. According to the obtained results apart from the instrumental manifestation of $T_{\mathrm{g}}$, the glassy phase indeed changes its properties/relaxes even above $T_{\mathrm{g}, \mathrm{s}}$ and the relative relaxation speed increases as the temperature approaches $T_{\mathrm{g}, \mathrm{f}}$. One can suggest that the glassy phase tends to be more like a liquid with time. On the other hand, the absolute relaxation-time values are higher in the middle of the glass-transition region.

The interesting question, however, is how far can the glassy phase relax in the glass-transition region and if we can expect it to ever reach the liquid state below $T_{\mathrm{g}, \mathrm{f}}$ ? $T_{\mathrm{g}, \mathrm{s}}$ decreases faster than $T_{\mathrm{g}, \mathrm{f}}$ with annealing time, and therefore this transformation may not be ever realized, at least in these cases. But, if the rate of decrease in $T_{\mathrm{g}, \mathrm{s}}$ is slower than that of $T_{\mathrm{g}, \mathrm{f}}$, then only it may be possible for the glass to reach the true liquid state.

Hysteresis which is very well seen in the samples heated and cooled at continuous scan mode is much less pronounced if the sample is studied under step-scan mode (Fig. 7) when the heating and cooling traces almost coincide.

\section{CONCLUSIONS}

In the present paper, the glass-transition phenomenon in a Zr-based metallic glass has been studied using a step-scan calorimetry technique. The clear existence of two slopes within the glass-transition region between $T_{\mathrm{g}, \mathrm{s}-1}$ and $T_{\mathrm{g}, \mathrm{f}}$ indicates the occurrence of two glass-transition processes. These two processes occurring one at low temperatures and the other at high temperatures, indicate two relaxations competing with each other. This phenomenon is likely related to the different diffusion coefficients (mobility) of the alloying elements.

Relaxation of the glassy phase toward liquidlike behavior takes place in the glass-transition region. According to the obtained results apart from the instrumental manifestation of $T_{\mathrm{g}}$, the glassy phase indeed changes its properties/relaxes even above $T_{\mathrm{g}, \mathrm{s}}$ and the relative relaxation speed increases as the temperature approaches $T_{\mathrm{g}, \mathrm{f}}$. One can suggest that the glassy phase tends to be more like a liquid with time. On the other hand, the absolute relaxation-time values are higher in the middle of the glass-transition region.

\section{ACKNOWLEDGMENTS}

The authors sincerely thank A. R. Yavari (SIMAPLTPCM Grenoble), A. Takeuchi (WPI-AIMR), and J. Perepezko (Univ. Madison-Wisconsin) for fruitful discussions. This work was supported in part by the Research and Development Project on Advanced Metallic Glasses, Inorganic Materials and Joining Technology, MEXT, Japan.

\footnotetext{
*FAX: +081 (22) 217-5956; dml@wpi-aimr.tohoku.ac.jp

${ }^{1}$ W. Klement, R. H. Willens, and P. Duwez, Nature (London) 187, 869 (1960).

${ }^{2}$ P. G. Le Comber, A. Madan, and W. E. Spear, in Electronic and Structural Properties of Amorphous Semiconductors, edited by P. G. Le Comber and J. Mort (Academic Press, London, New York, 1973), Vol. 373.

${ }^{3}$ D. V. Louzguine-Luzgin andA. Inoue, J. Nanosci. Nanotechnol.
}

5, 999 (2005).

${ }^{4}$ A. Inoue, Mater. Trans., JIM 36, 866 (1995).

${ }^{5}$ W. L. Johnson, MRS Bull. 24, 42 (1999).

${ }^{6}$ A. Inoue, Acta Mater. 48, 279 (2000).

${ }^{7}$ C. Suryanarayana and A. Inoue, Bulk Metallic Glasses (CRC Press, Boca Raton, FL, 2010).

${ }^{8}$ D. B. Miracle, W. S. Sanders, and O. N. Senkov, Philos. Mag. 83, 2409 (2003). 
${ }^{9}$ H. W. Sheng, W. K. Luo, F. M. Alamgir, J. M. Bai, and E. Ma, Nature (London) 439, 419 (2006).

${ }^{10}$ D. Turnbull, Contemp. Phys. 10, 473 (1969).

${ }^{11}$ C. A. Angell, J. Non-Cryst. Solids 102, 205 (1988).

${ }^{12}$ T. Egami, J. Non-Cryst. Solids 317, 30 (2003).

${ }^{13}$ P. G. Debenedetti and F. H. Stillinger, Nature (London) 410, 259 (2001).

${ }^{14}$ C. A. Angell, Encyclopedia of Materials: Science and Technology (Pergamon, New York, 2001), Vol 4, p. 3365.

${ }^{15}$ M. H. Cohen and G. S. Grest, Phys. Rev. B 20, 1077 (1979).

${ }^{16}$ A. van den Beukel and J. Sietsma, Acta Metall. Mater. 38, 383 (1990).

${ }^{17}$ W. Kauzmann, Chem. Rev. 43, 219 (1948).

${ }^{18}$ E. Leutheusser, Phys. Rev. A 29, 2765 (1984).

${ }^{19}$ J. K. Krüger et al., Lect. Notes Phys. 716, 61 (2007).

${ }^{20}$ Y. Moriya, T. Yoshida, H. Kawaji, T. Atake, M. Fukuhara, H. Kimura, and A. Inoue, Mater. Sci. Eng., B 148, 207 (2008).
${ }^{21}$ I. Seki, D. V. Louzguine-Luzgin, and A. Inoue, Mater. Trans. 48, 821 (2007).

${ }^{22}$ R. G. Palmer, Adv. Phys. 31, 669 (1982).

${ }^{23}$ A. R. Yavari, A. Le Moulec, A. Inoue, N. Nishiyama, N. Lupu, E. Matsubara, W. J. Botta, G. Vaughan, M. Di Michiel, and A. Kvick, Acta Mater. 53, 1611 (2005).

${ }^{24}$ T. Yamasaki, S. Maeda, Y. Yokoyama, D. Okai, T. Fukami, H. M. Kimura and A. Inoue, Intermetallics 14, 1102 (2006).

${ }^{25}$ K. L. Ngai and S. Capaccioli, J. Am. Ceram. Soc. 91, 709 (2008).

${ }^{26}$ I. M. Hodge, J. Am. Ceram. Soc. 91, 766 (2008).

${ }^{27}$ M. Dzugutov, Europhys. Lett. 26, 533 (1994).

${ }^{28}$ K. Knorr, M.-P. Macht, K. Freitag, and H. Mehrer, J. Non-Cryst. Solids 250-252, 669 (1999).

${ }^{29}$ T. Egami, Mater. Trans. 43, 510 (2002).

${ }^{30}$ O. Haruyama, N. Nakayama, R. Wada, H. Tokunaga, J. Okada, T. Ishikawa, and Y. Yokoyama, Acta Mater. 58, 1829 (2010). 